Editorial

\title{
Psychopathy, sociopathy, and antisocial personality disorder
}

\section{Editorial}

The terms psychopathy, sociopathy, and antisocial personality disorder (ASPD) are commonly used interchangeably in clinical and research literature as well as the popular media. Further complicating matters, the diagnostic features section of ASPD in the American Psychiatric Association's (APA) Diagnostic and Statistical Manual of Mental Disorders, Fifth Edition (DSM-5) ${ }^{1}$ indicates that ASPD “...has also been referred to as psychopathy, sociopathy, or dyssocial personality disorder" (p. 659). However, the consensus among most researchers is that ASPD, psychopathy, and sociopathy are related but distinct constructs. $^{2-5}$ Dissocial [sic] personality disorder is currently listed in the World Health Organization's (WHO) ICD-10 Classification of Mental and Behavioural Disorders: Clinical Descriptions and Diagnostic Guidelines (ICD-10) and, similar to the DSM, indicates the diagnosis includes amoral, antisocial, asocial, psychopathic, and sociopathic personality disorders. ${ }^{6}$ The construct of psychopathy dates back to ancient times. It was described by Theophrastus, a student of Aristotle, and was the first personality disorder to be recognized in psychiatry. ${ }^{7}$

During the early 19th century, Pinel described patients who exhibited a lack of restraint despite being aware of the consequences of their behavior as having manie sans delire (insanity without delirium). Cleckley $^{8}$ published The Mask of Sanity describing the features of psychopathy that served as the foundation for current research in the field. ${ }^{8}$ Hare $^{9}$ developed the Psychopathy Checklist-Revised (PCL-R), which was influenced by the previous work of Cleckley. The PCL-R is a reliable and valid instrument that consists of 20 items and is completed using a semi structured interview and a review of collateral information to assess a distinctive pattern of interpersonal (e.g., glibness/superficial charm), behavioral (e.g., irresponsibility), and affective (e.g., callousness/lack of empathy) features of psychopathy. ${ }^{2,9,10}$ The two-factor structure of the PCL-R allows clinicians and researchers to distinguish between personality characteristics (Factor 1) and behavioral characteristics (Factor 2). Psychopathy can also be assessed categorically or dimensionally.,11 Current research suggests that psychopathy is innate; the etiology of which includes a heavy biological loading. ${ }^{4,12-14}$

The first edition of the DSM in 1952 included the diagnosis of Sociopathic Personality Disturbance, which included many of the features of psychopathy originally described by Cleckley. ${ }^{15}$ Included under the diagnosis were the distinctions of antisocial and dyssocial sociopaths. Antisocial sociopaths referred to common offenders and dyssocial sociopaths included white-collar criminals. However, the diagnosis evolved to reflect the changing attitudes of the era that suggested criminality was due to environmental factors, in particular, a lack of socialization. ${ }^{4}$ The dyssocial sociopathic distinction was eliminated in the second edition of the DSM in 1968, and many of the features of psychopathy remained. In 1980 with the publication of the DSM-III, only the term ASPD was used, and the diagnostic criteria were changed to reflect behavioral characteristics rather than
Volume 2 Issue 2 - 2016

\author{
Richard P Conti \\ Department of Psychology, Kean University, USA
}

Correspondence: Richard P Conti, Department of Psychology, Kean University, 1000 Morris Avenue, Union, NJ 07083, USA, Tel 908-737-5870, Fax 908-737-5875, Email rconti@kean.edu

Received: February 01, 2016 | Published: February 9, 2016

personality traits. This revision also required the diagnosis of Conduct Disorder before the age of 15 to meet the diagnostic criteria of ASPD. ${ }^{15}$

Currently, the DSM-5' defines ASPD as a "pervasive pattern of disregard for, and violation of, the rights of others that begins in childhood or early adolescence and continues into adulthood" (p. 659). In order to meet the diagnosis, an individual must be at least 18 years of age, have a history of Conduct Disorder before age 15, and meet three of seven of the following criteria:
i. Failure to conform to social norms;
ii. Deceitfulness;
iii. Impulsivity;
iv. Irritability and aggressiveness;
v. Reckless disregard for safety;
vi. Consistent irresponsibility; and
vii. Lack of remorse.

Although some of these diagnostic criteria overlap with psychopathy (as measured by the PCL-R), they have been criticized as being too focused on antisocial behavior, whereas the PCL-R encompasses both personality traits and antisocial behaviors. ${ }^{16}$ The ASPD criteria correlate strongly with the PCL-R behavioral characteristics (Factor 2) and weakly with PCL-R personality characteristics (Factor 1$){ }^{2}$

The prevalence rates of the disorders also differ. Roughly $50 \%$ to $80 \%$ of offenders and forensic patients meet the diagnostic criteria for ASPD, whereas only $15 \%$ to $30 \%$ of offenders meet the PCL-R diagnostic criteria for psychopathy. ${ }^{2,3,17}$ In addition, an asymmetric link exists between ASPD and psychopathy. Most offenders (about 90\%) diagnosed as psychopaths by PCL-R criteria meet the criteria for ASPD, while a minority (about $30 \%$ ) of those with ASPD meet the PCL-R criteria for psychopathy. ${ }^{2,18}$ The present consensus suggests that psychopathy and ASPD are separate but related disorders. Sociopathy is an outdated term that infrequently appears in the scientific research literature and is more related to ASPD due to the emphasis on behavioral characteristics. Recent research has begun to 
examine psychopathic traits in non-forensic populations, ${ }^{19-21}$ further emphasizing that antisocial behavior is not equivalent to psychopathy.

\section{Acknowledgments}

None.

\section{Conflicts of interest}

The author declares that there are no conflicts of interest.

\section{References}

1. Cardwell CN. Diagnostic and statistical manual of mental disorders, 5th ed. Arlington, American Psychiatric Publishing, USA. 2013;128 p.

2. Hare RD. Psychopathy: A clinical and forensic overview. Psychiatr Clin North Am. 2006;29(3):709-724.

3. Hare RD, Neumann CS. Psychopathy as a clinical and empirical construct. Annu Rev Clin Psychol. 2008;4:217-246.

4. Lykken DT. The antisocial personalities. Lawrence Erlbaum Associates, Erlbaum, USA. 1995;272.

5. Skeem JL, Polaschek DL, Patrick CJ, et al. Psychopathic personality: Bridging the gap between scientific evidence and public policy. Psychol Sci Public Interest. 2011;12(3):95-162.

6. World Health Organization. The ICD-10 classification of mental and behavioural disorders: Clinical descriptions and diagnostic guidelines. Geneva, Switzerland, Europe. 1992;1-267 p.

7. Millon T, Simonsen E, Birket-Smith M. Historical conceptions of psychopathy in the United States and Europe. In: Millon T, editor. Psychopathy: Antisocial, criminal, and violent behavior (3-31). Guilford Press, New York, USA. 1998.

8. Cleckley H. The mask of sanity, 6th ed. Mosby publishers, USA. 1976.
9. Hare RD. The Hare Psychopathy Checklist: Revised. Multi-Health Systems, Toronto, Canada. 1991.

10. Hare RD. Psychopathy: A clinical construct whose time has come. Crim Justice Behav. 1997;23(1):25-54.

11. Gacono CB. The clinical and forensic assessment of psychopathy: A practitioner's guide. Mahwah, NJ: Erlbaum. 2000.

12. Glenn AL, Raine A. Psychopathy: An introduction to biological findings and their implications. Int J Soc Psychiatry. 2014;60(3):728-729.

13. Meloy JR. The psychopathic mind: Origins, dynamics, and treatment. Aronson publications, Northvale, USA. 1988;474 p.

14. Raine A. The psychopathology of crime: Criminal behavior as a clinical disorder. Academic Press, USA. 1993;377 p.

15. Arrigo BA, Shipley S. The confusion over psychopathy (I): Historical considerations. Int J Offender Ther Comp Criminol. 2001;45(3):325-344.

16. Widiger TA, Cadoret R, Hare RD, et al. DSM-IV antisocial personality disorder field trial. J Abnorm Psychol. 1996;105(1):3-16.

17. Robins LN, Tipp J, Przybeck T. Antisocial personality. In: LN Robins, Regier D, editors. Psychiatric disorders in America. Free Press, New York, USA. 1991;258-290 p.

18. Hare RD, Hart SD. Violent and aggressive behavior in criminal psychopaths. Int J Law Psychol. 1989;7(1):35-50.

19. Babiak P, Hare RD. Snakes in suits: When psychopaths go to work. Harper Collins, New York, USA. 2007;1-355.

20. Lilienfeld SO, Andrews BP. Development and preliminary validation of a self-report measure of psychopathic personality traits in noncriminal populations. J Pers Assess. 1996;66(3):488-524.

21. Lilienfeld SO, Widows M. Professional Manual for the Psychopathic Personality Inventory-Revised (PPI-R). Fl: Psychological Assessment Resources. Lutz. 2005. 